\title{
Exogenous abscisic acid increases antioxidant enzymes and related gene expression in pepper (Capsicum annuum) leaves subjected to chilling stress
}

\author{
W.L. Guo ${ }^{1,2 *}$, R.G. Chen ${ }^{1,2 *}$, Z.H. Gong ${ }^{1,2}$, Y.X. Yin ${ }^{1,2}$, S.S. Ahmed ${ }^{1}$ and \\ Y.M. $\mathrm{He}^{1}$ \\ ${ }^{1}$ College of Horticulture, Northwest A \& F University, \\ Yangling, Shaanxi, P.R. China \\ ${ }^{2}$ State Key Laboratory of Crop Stress Biology in Arid Areas, \\ Northwest A \& F University, P.R. China \\ *These authors contributed equally to this study. \\ Corresponding author: Z.H. Gong \\ E-mail: gzhh168@yahoo.com.cn
}

Genet. Mol. Res. 11 (4): 4063-4080 (2012)

Received January 23, 2012

Accepted May 25, 2012

Published September 10, 2012

DOI http://dx.doi.org/10.4238/2012.September.10.5

\begin{abstract}
To elucidate how physiological and biochemical mechanisms of chilling stress are regulated by abscisic acid (ABA) pretreatment, pepper variety (cv. 'P70') seedlings were pretreated with $0.57 \mathrm{mM} \mathrm{ABA}$ for $72 \mathrm{~h}$ and then subjected to chilling stress at $10^{\circ} / 6^{\circ} \mathrm{C}$ (day/night). Chilling stress caused severe necrotic lesions on the leaves and increased malondialdehyde and $\mathrm{H}_{2} \mathrm{O}_{2}$ levels. Activities of monodehydroascorbate reductase (DHAR), dehydroascorbate reductase, glutathione reductase, guaiacol peroxidase, ascorbate peroxidase, ascorbate, and glutathione increased due to chilling stress during the $72 \mathrm{~h}$, while superoxide dismutase and catalase activities decreased during $24 \mathrm{~h}$, suggesting that chilling stress activates the AsA-GSH cycle under catalase deactivation in pepper leaves. ABA
\end{abstract}


pretreatment induced significant increases in the above-mentioned enzyme activities and progressive decreases in ascorbate and glutathione levels. On the other hand, ABA-pretreated seedlings under chilling stress increased superoxide dismutase and guaiacol peroxidase activities and lowered concentrations of other antioxidants compared with untreated chilling-stressed plants. These seedlings showed concomitant decreases in foliage damage symptoms, and levels of malondialdehyde and $\mathrm{H}_{2} \mathrm{O}_{2}$. Induction of $M n-S O D$ and $P O D$ was observed in chilling-stressed plants treated with ABA. The expression of DHAR1 and DHAR2 was altered by chilling stress, but it was higher in the presence than in the absence of ABA at 24 h. Overall, the results indicate that exogenous application of ABA increases tolerance of plants to chilling-induced oxidative damage, mainly by enhancing superoxide dismutase and guaiacol peroxidase activities and related gene expression.

Key words: Abscisic acid; Antioxidant system; Chilling stress; Gene expression; Capsicum annuum L.

\section{INTRODUCTION}

Temperature plays a critical role in plant growth. Low or high temperature stress is frequent throughout the year. Some high-value vegetable crops of tropical or subtropical origin, such as the pepper plant (Capsicum annuиm L.), are sensitive to cold temperatures. The optimum temperature for the growth of pepper ranges between $21^{\circ}$ and $27^{\circ} \mathrm{C}$, and growth is retarded below $12^{\circ} \mathrm{C}$ and above $30^{\circ} \mathrm{C}$ (Korkmaz et al., 2010). Chilling stress affects a multitude of physiological and biochemical processes, causing poor germination, slow growth, discoloration or yellowing, withering, necrotic lesions, and membrane disintegration. Chilling stress is also manifested as an oxidative stress mediated by reactive oxygen species (ROS). The accumulation of ROS has been proposed to damage the morphological structure and physiological metabolism of plants. To keep excess ROS under homeostatic control, plants have antioxidative enzymes and metabolites, including superoxide dismutase (SOD), catalase (CAT), guaiacol peroxidase (POD), ascorbate peroxidase (APX), glutathione reductase (GR), dehydroascorbate reductase (DHAR), and monoDHAR (MDHAR), as well as antioxidants, such as reduced glutathione (GSH) and ascorbate (AsA). Chilling injury has been shown to lead to cellular stress and oxidation of cellular components such as the AsA pool (Hodges et al., 2004).

AsA is a crucial antioxidant in plant cells that acts either directly as a free radical scavenger or indirectly as an electron donor to APX during the enzymatic reduction of $\mathrm{H}_{2} \mathrm{O}_{2}$. The AsA-GSH cycle includes the cooperative enzymes APX, MDHAR, DHAR, and GR. The majority of earlier experiments have focused mostly on the activity of the enzymes involved in the AsA-GSH cycle during abiotic stresses (Selote and Khanna-Chopra, 2006; Stevens, 2008). The increase in MDHAR activity contributes to chilling tolerance in tomato fruit (Stevens, 2008). Recently, the overexpression of a DHAR gene has been shown to increase AsA levels and enhance cold tolerance in tobacco (Le Martret et al., 2011). However, studies of this kind have been limited thus far in horticultural crops (Li et al., 2010). 
Abscisic acid (ABA), as a stress signal, enhances the tolerance of plants to several environmental stresses, including low temperature (Verslues and Zhu, 2005), salt (Bellaire et al., 2000), and drought (Ma et al., 2008). The increased tolerance is partly due to an enhanced antioxidant defense system that includes SOD, CAT, APX, and GR (Bellaire et al., 2000), and the AsA and GSH, which prevent the accumulation of ROS (Jiang and Zhang, 2002). Stylosanthes guianensis seedlings pretreated with ABA show increased chilling tolerance via increases in SOD activity and AsA and GSH levels, which provide little information about how AsA-GSH metabolism (e.g., APX, MDHAR, DHAR, and GR) regulates the scavenging of excess ROS (Zhou et al., 2005). ABA-mediated upregulation of genes such as APX, MDHAR, GR, and DHAR in Arabidopsis thaliana is involved in ROS scavenging through the AsA-GSH cycle, and ABAmediated AsA accumulation appear to be regulated by enhanced recycling at the transcriptional level (Ghassemian et al., 2008). However, little knowledge exists about whether ABA pretreatment enhances the tolerance of plants to chilling stress via AsA-GSH metabolism. Moreover, no specific information is available regarding the effects of chilling stress on antioxidants (AsA and $\mathrm{GSH}$ ) and how relevant ROS-scavenging enzymes regulate the regeneration of AsA in pepper. Therefore, to understand the tolerance mechanism of pepper seedlings under chilling stress, we investigated the effects of exogenous $\mathrm{ABA}$ on lipid peroxidation, $\mathrm{H}_{2} \mathrm{O}_{2}$, total antioxidant activity, and specific activities of key enzymes of AsA-GSH metabolism in pepper seedlings. Additionally, the effect of ABA and chilling stress on the expression of the genes Mn-SOD, POD, DHARl, and DHAR2 was analyzed using quantitative real-time polymerase chain reaction (qRT-PCR).

\section{MATERIAL AND METHODS}

\section{Plant material, ABA treatments, and induced chilling stress}

'P70' is a typical pepper cultivar that is fairly tolerant of low temperatures. Seeds of cv. 'P70' peppers obtained from Northwest A \& F University (Yangling, China) were soaked in warm water $\left(50^{\circ}-60^{\circ} \mathrm{C}\right)$ for approximately $20 \mathrm{~min}$ to promote germination. The seeds were rinsed twice every $24 \mathrm{~h}$ and then placed on moist gauze in an incubator $\left(25^{\circ}-28^{\circ} \mathrm{C}\right.$ and $60-80 \%$ relative humidity in darkness).

When the seeds were at least $80 \%$ germinated, they were sown at a depth of $1.0 \mathrm{~cm}$ into 9-cm-deep plastic pots filled with growth medium consisting of grass charcoal and perlite in a ratio of $3: 1$. The seedlings were watered regularly with tap water and kept in a growth chamber at $25^{\circ} \pm 1{ }^{\circ} \mathrm{C} / 18^{\circ} \pm 1^{\circ} \mathrm{C}$ (day/night) with a 12 -h light $(20,000 \mathrm{~lx})$ and 12 -h dark cycle per day. When the seedlings had developed 6-8 true leaves (approximately 45 days after planting), half of the seedlings were sprayed with freshly prepared $0.57 \mathrm{mM} \mathrm{ABA}$ solution until both sides of the leaves were completely wet; the other half was sprayed with distilled water from 0900 to 1000 . For foliar application, $0.5 \%$ Tween-20 was added to the ABA solution to increase adherence. Three days after foliar application, the plants were subjected either to chilling stress at $10^{\circ} / 6^{\circ} \mathrm{C}$ (day/night) under a 5500-lx light or to room temperatures at $25^{\circ} / 18^{\circ} \mathrm{C}$ (day/night) under a $20,000-1 \mathrm{X}$ light.

Therefore, the plants were submitted to 4 treatments: CK (not pretreated with ABA and not exposed to chilling stress); $\mathrm{ABA}$ (pretreated with $\mathrm{ABA}$ and not exposed to chilling stress); chilling (not pretreated with $\mathrm{ABA}$ and exposed to chilling stress), and $\mathrm{ABA}+$ chilling (pretreated with $\mathrm{ABA}$ and exposed to chilling stress). The treatments were repeated 4 times with 12 plants in each group, and all treatments were arranged in a randomized complete block 
design. All plants were assessed $48 \mathrm{~h}$ after the end of $48 \mathrm{~h}$ of chilling stress to determine the extent of chilling injury. To evaluate the change in metabolism at various times during the chilling treatment $(0,1,3,6,12,24,48,72$, and $120 \mathrm{~h})$, samples of upper, fully expanded leaves were ground with liquid nitrogen for experimentation.

\section{Determination of visual damage}

All plants were visually examined to determine the extent of chilling damage and classified using the following scale: none, no visible symptoms; slight, small necrotic areas on the shoots but no growth restrictions ( $<5 \%$ of the leaf area was necrotic); moderate, welldefined necrotic areas on shoots ( $5-25 \%$ of the leaf area was necrotic); severe, extensive necrotic areas and severe growth reduction (26-50\% of the leaf area was necrotic but the plant was still alive), and killed, the entire plant was necrotic and collapsed. By assigning values of $1,2,3,4$, and 5 , respectively, to each group, the average chilling injury (CI) for each treatment was calculated using the following formula (Korkmaz et al., 2010):

in the treatment.

$\mathrm{CI}$ index $=\sum[(\mathrm{CI}$ level) $\mathrm{x}$ (number of plants at the $\mathrm{CI}$ level) $] /$ total number of plants

\section{Determination of lipid peroxidation [malondialdehyde (MDA)]}

The amount of lipid peroxidation product on the chloroplastic membranes was estimated by measuring the amount of MDA produced by the thiobarbituric acid reaction according to the methods described by Dhindsa et al. (1981), with some modifications. The crude extract was mixed with the same volume of a $0.5 \%(\mathrm{w} / \mathrm{v})$ thiobarbituric acid solution containing $5 \%(\mathrm{w} / \mathrm{v})$ trichloroacetic acid. The mixture was heated at $100^{\circ} \mathrm{C}$ for $15 \mathrm{~min}$, cooled quickly, and centrifuged at 10,000 rpm for $10 \mathrm{~min}$. The supernatant was used to measure the absorbance at 532,600, and $450 \mathrm{~nm}$. The MDA concentration was calculated according to the following formula: $[\mathrm{MDA}]=6.45 \times(\mathrm{A} 532-\mathrm{A} 600)-0.56 \times \mathrm{A} 450$.

\section{Determination of hydrogen peroxide $\left(\mathrm{H}_{2} \mathrm{O}_{2}\right)$ level}

$\mathrm{H}_{2} \mathrm{O}_{2}$ level was measured according to the method of Mukherjee and Choudhuri (1983), with some modifications. Samples of the leaves were cut from the pepper seedlings and immediately ground with liquid nitrogen. Then, $1.0 \mathrm{~g}$ ground powder was homogenized in $2 \mathrm{~mL}$ cold $\left(-20^{\circ} \mathrm{C}\right)$ acetone and centrifuged at $12,000 \mathrm{rpm}$ for $10 \mathrm{~min}$ at $4^{\circ} \mathrm{C}$. One milliliter of the supernatant was mixed with $0.2 \mathrm{~mL} \mathrm{NH}_{3}$ and $0.1 \mathrm{~mL} \mathrm{95 \% (v/v)} \mathrm{HCl}$ containing $20 \%$ $(\mathrm{v} / \mathrm{v}) \mathrm{TiCl}_{4}$. After being centrifuged again, the sediment was washed twice with cold $\left(-20^{\circ} \mathrm{C}\right)$ acetone to make the pigment disappear. The mixture was then centrifuged at $6000 \mathrm{rpm}$ for 5 min at $4{ }^{\circ} \mathrm{C}$, and the resulting sediment was dissolved in $3 \mathrm{~mL} 2 \mathrm{M} \mathrm{H}_{2} \mathrm{SO}_{4}$. The absorbance of the resulting solution was measured at $410 \mathrm{~nm}$, and the level of $\mathrm{H}_{2} \mathrm{O}_{2}$ in the leaves was calculated with an $\mathrm{H}_{2} \mathrm{O}_{2}$ solution-derived standard curve.

\section{Extraction of metabolites of the AsA-GSH cycle}

Lyophilized leaf powder $(1.00 \mathrm{~g})$ was ground in a mortar and homogenized with $5 \mathrm{~mL}$ 
ice-cold extraction buffer [50 $\mathrm{mM}$ potassium phosphate buffer, $\mathrm{pH}$ 7.6, $5 \mathrm{mM}$ ethylenediaminetetraacetic acid (EDTA), $5 \mathrm{mM}$ AsA, and $4 \%$ polyvinylpyrrolidone]. The homogenate was centrifuged at $13,000 \mathrm{rpm}$ for $20 \mathrm{~min}$ at $4^{\circ} \mathrm{C}$. The supernatant fraction was used as a crude extract for enzyme activity assays. All operations were carried out at $4^{\circ} \mathrm{C}$.

APX activity was determined by monitoring the decrease in absorbance at $290 \mathrm{~nm}$ for $1 \mathrm{~min}$ as AsA was oxidized [extinction coefficient of $2.8 \mathrm{mM} / \mathrm{cm}$ (Nakano and Asada, 1981)]. The reaction mixture $(1.5 \mathrm{~mL})$ contained $50 \mathrm{mM}$ phosphate buffer, $\mathrm{pH}$ 7.0, $0.1 \mathrm{mM}$ EDTA, 0.5 $\mathrm{mM}$ AsA, $1 \mathrm{mM} \mathrm{H}_{2} \mathrm{O}_{2}$, and $40 \mu \mathrm{L}$ enzyme extract. The reaction was initiated by adding $\mathrm{H}_{2} \mathrm{O}_{2}$, and the results are reported as $\mathrm{mM} \mathrm{H}_{2} \mathrm{O}_{2} \cdot \mathrm{min}^{-1} \cdot \mathrm{g}^{-1}$ fresh weight (FW).

MDHAR activity was assayed by monitoring the decrease in absorbance at $340 \mathrm{~nm}$ owing to reduced nicotinamide adenine dinucleotide (NADH) oxidation [extinction coefficient of $6.2 \mathrm{mM} / \mathrm{cm}$ (Arrigoni et al., 1981)]. The 1-mL assay solution contained $50 \mathrm{mM}$ HEPES-KOH, pH 7.6, $2.5 \mathrm{mM}$ AsA, $0.1 \mathrm{mM}$ NADH, $0.5 \mathrm{U}$ AsA oxidase, and $100 \mu \mathrm{L}$ enzyme extract. The reaction was initiated by adding AsA oxidase, and the results are reported as $\mathrm{mmol} \mathrm{NADH} \cdot \mathrm{min}^{-1} \cdot \mathrm{g}^{-1} \mathrm{FW}$.

DHAR activity was determined by monitoring the increase in absorbance at $265 \mathrm{~nm}$ owing to AsA formation [extinction coefficient of $14 \mathrm{mM} / \mathrm{cm}$ (Nakano and Asada, 1981)]. A 1.5-mL reaction solution contained $50 \mathrm{mM}$ phosphate buffer, $\mathrm{pH}$ 7.0, $2.5 \mathrm{mM}$ GSH, $0.1 \mathrm{mM}$ EDTA, $0.2 \mathrm{mM}$ dehydroascorbate (DHA), and $60 \mu \mathrm{L}$ enzyme extract. The reaction was initiated by adding DHA, and the results are reported as $\mathrm{mmol} \mathrm{AsA} \cdot \mathrm{min}^{-1} \cdot \mathrm{g}^{-1} \mathrm{FW}$.

GR activity was assayed by monitoring the decrease in absorbance at $340 \mathrm{~nm}$ owing to reduced nicotinamide adenine dinucleotide phosphate (NADPH) oxidation [extinction coefficient of $6.2 \mathrm{mM} / \mathrm{cm}$ (Schaedle, 1977)]. The 1-mL reaction mixture contained $50 \mathrm{mM}$ phosphate buffer, pH 7.6, 0.4 mM EDTA, 0.2 mM NADPH, 0.5 mM oxidized GSH (GSSG), and $75 \mu \mathrm{L}$ enzyme extract. The reaction was initiated by adding NADPH, and the results are reported as $\mathrm{mmol} \mathrm{NADPH} \cdot \mathrm{min}^{-1} \cdot \mathrm{g}^{-1} \mathrm{FW}$.

\section{Determination of AsA and GSH levels}

AsA was measured according to the method described by Logan et al. (1998). Briefly, leaves $(0.3 \mathrm{~g})$ were homogenized with $0.9 \mathrm{~mL}$ ice-cold $6 \% \mathrm{HClO}_{4}$ and centrifuged at 12,000 $\mathrm{rpm}$ for $20 \mathrm{~min}$ at $4^{\circ} \mathrm{C}$. The extract $(100 \mu \mathrm{L})$ was neutralized with $20 \mu \mathrm{L} 1.5 \mathrm{M} \mathrm{Na}_{2} \mathrm{CO}_{3}$ to raise the $\mathrm{pH}$ to 1-2. AsA was calculated spectrophotometrically at $265 \mathrm{~nm}$ in $200 \mathrm{mM}$ sodium acetate buffer, $\mathrm{pH}$ 5.6, before and after a 15-min incubation with $1.5 \mathrm{U}$ AsA oxidase.

Reduced GSH and GSSG were measured according to the method described by Griffith (1980), with minor modification. Leaves weighing $0.2 \mathrm{~g}$ were ground with 0.6 $\mathrm{mL} \mathrm{5 \%} \mathrm{sulfosalicylic} \mathrm{acid} \mathrm{and} \mathrm{centrifuged} \mathrm{at} 12,000 \mathrm{rpm}$ for $20 \mathrm{~min}$ at $4^{\circ} \mathrm{C}$. For total GSH measurement, the reaction solution contained $200 \mu \mathrm{L} 0.5 \mathrm{M}$ sodium phosphate buffer (6.3 mM EDTA, pH 7.5), $560 \mu \mathrm{L} 10 \mathrm{mM}$ EDTA, $100 \mu \mathrm{L} 6 \mathrm{mM}$ DTNB (5,5'-dithiobis 2-nitrobenzoic acid) dissolved in phosphate buffer, $100 \mu \mathrm{L} 2.1 \mathrm{mM} \mathrm{NADPH}$, and $20 \mu \mathrm{L}$ supernatant. The reaction was initiated by adding $1 \mathrm{U}$ GR and measured at $412 \mathrm{~nm}$. For GSSG measurement, $20 \mu \mathrm{L}$ supernatant was mixed with $200 \mu \mathrm{L}$ phosphate buffer and 4 $\mu \mathrm{L} 2$-vinylpyridine and incubated at $25^{\circ} \mathrm{C}$ for $30 \mathrm{~min}$ to remove $\mathrm{GSH}$ via derivatization. GSSG was assayed as described above for the total GSH. GSH was determined by subtracting GSSG from the total GSH content. 


\section{Extract preparation for antioxidative enzymes}

Lyophilized leaf $(1.00 \mathrm{~g})$ powder was ground in a mortar and homogenized with $5 \mathrm{~mL}$ ice-cold extraction buffer (100 mM potassium phosphate buffer, $\mathrm{pH} 7.5,1 \mathrm{mM}$ EDTA, and 4\% polyvinylpyrrolidone). The homogenate was centrifuged at $13,000 \mathrm{rpm}$ for $20 \mathrm{~min}$ at $4^{\circ} \mathrm{C}$. The supernatant fraction was used as a crude extract for enzyme activity assays. All procedures were carried out at $4^{\circ} \mathrm{C}$.

Total SOD activity was assayed by monitoring the inhibition of the photochemical reduction of nitroblue tetrazolium (NBT) according to the method described by Giannopolitis and Ries (1977), with minor modification. A 1-mL reaction mixture contained $50 \mathrm{mM}$ potassium phosphate buffer, $\mathrm{pH}$ 7.8, $6.5 \mathrm{mM}$ methionine, $50 \mu \mathrm{M}$ NBT, $20 \mu \mathrm{M}$ riboflavin, $10 \mu \mathrm{M}$ EDTA, and $55 \mu \mathrm{L}$ enzyme extract. The reaction mixture without enzymes was used as a control. All of the reaction mixtures in the small test tubes were mixed well in the dark and then irradiated for $5 \mathrm{~min}$ at $600 \mu \mathrm{mol} \cdot \mathrm{m}^{-2} \cdot \mathrm{s}^{-1}$ photon flux density. The absorbance was measured at $560 \mathrm{~nm}$, and the absorbance of the reaction mixture without enzymes and irradiation was subtracted from each of the samples. One unit of SOD activity was defined as the amount of enzyme required to inhibit $50 \%$ of the NBT photo reduction at $560 \mathrm{~nm}$.

Total CAT activity was determined by monitoring the decrease in absorbance at 240 $\mathrm{nm}$ owing to the decomposition of $\mathrm{H}_{2} \mathrm{O}_{2}$ [extinction coefficient of $39.4 \mathrm{mM} / \mathrm{cm}$ (Aebi, 1984)]. The 1-mL reaction mixture consisted of $50 \mathrm{mM}$ potassium phosphate buffer, $\mathrm{pH} 7.0,10 \mathrm{mM}$ $\mathrm{H}_{2} \mathrm{O}_{2}$ (freshly prepared), and $50 \mu \mathrm{L}$ enzyme extract. The reaction was initiated by adding $\mathrm{H}_{2} \mathrm{O}_{2}$, and the results are reported as $\mu \mathrm{mol} \mathrm{H}_{2} \mathrm{O}_{2} \cdot \mathrm{s}^{-1} \cdot \mathrm{g}^{-1} \mathrm{FW}$.

Total POD activity was assayed by monitoring the increase in absorbance at $470 \mathrm{~nm}$ owing to guaiacol oxidation [extinction coefficient of $26.8 \mathrm{mM} / \mathrm{cm}$ (Hammerschmidt et al., 1982)]. The $1-\mathrm{mL}$ reaction mixture contained $50 \mathrm{mM}$ sodium phosphate buffer, $\mathrm{pH} 7.0,10$ $\mathrm{mM} \mathrm{H}_{2} \mathrm{O}_{2}, 10 \mathrm{mM}$ guaiacol, and $50 \mu \mathrm{L}$ enzyme extract. The reaction was initiated by adding $\mathrm{H}_{2} \mathrm{O}_{2}$, and the results are reported as $\mu \mathrm{mol} \mathrm{H}_{2} \mathrm{O}_{2} \cdot \mathrm{s}^{-1} \cdot \mathrm{g}^{-1} \mathrm{FW}$.

\section{RNA extraction and qRT-PCR for gene expression analysis}

Total RNA was isolated from pepper leaves with ABA and distilled water spray using the TRIZOL reagent (Invitrogen, USA) according to manufacturer instructions. The concentration of total RNA was measured spectrophotometrically using a NanoDrop instrument (Thermo Scientific NanoDrop 2000C Technologies, Wilmington, USA), and the purity was assessed using the $\mathrm{A}_{260} / \mathrm{A}_{280}$ and $\mathrm{A}_{260} / \mathrm{A}_{230}$ ratios provided by NanoDrop.

Reverse transcription was carried out using a PrimeScript ${ }^{\mathrm{TM}}$ first-strand complementary DNA (cDNA) Synthesis Kit (TaKaRa, Japan). qRT-PCR was performed with an iCycler $\mathrm{iQ}^{\mathrm{TM}}$ Multicolor PCR Detection System (Bio-Rad, Hercules, CA, USA). qPCR was carried out with cDNA in triplicate on 96-well plates using SYBR ${ }^{\circledR}$ Premix Ex Taq $^{\mathrm{TM}}$ II (TaKaRa). Each reaction $(20 \mu \mathrm{L})$ consisted of $10 \mu \mathrm{L} \mathrm{SYBR}^{\circledR}$ Premix Ex Taq ${ }^{\mathrm{TM}} \mathrm{II}, 2 \mu \mathrm{L}$ diluted cDNA, and $0.4 \mu \mathrm{M}$ forward and reverse primers. qPCR cycling conditions were as follows: $95^{\circ} \mathrm{C}$ for $1 \mathrm{~min}$ and $45 \mathrm{cycles}$ of $95^{\circ} \mathrm{C}$ for $15 \mathrm{~s}, 54^{\circ} \mathrm{C}$ for $20 \mathrm{~s}$, and $72^{\circ} \mathrm{C}$ for $30 \mathrm{~s}$. Fluorescence data were collected during the $54^{\circ} \mathrm{C}$ step. As reference genes, expression of beta tubulin and ubiquitin-conjugating protein was used for pepper (Wan et al., 2011). The accessions and primer sequences were: POD (FJ596178.1; forward, 5'-GCAGCATTCCTCCTCCTACT- 
3'; reverse, 5'-ATTTCTTTGCCTTGTTGTTG-3'); Mn-SOD (AF036936.2; forward, 5'-CT CTGCCATAGACACCAACTT-3'; reverse, 5'-CCAAGTTCGGTCCTTTAATAA-3'); DHAR1 (AY971873; forward, 5'-TATCAATGGGCAGAATGTTT-3'; reverse, 5'-TCTCTTCAGCCTT GGTTTTC-3'); DHAR2 (AY971874; forward, 5'-CCAAACCTCCGCTGACAAC-3'; reverse, 5'-AATCAGCAGCAGATACCTCAT-3'); beta tubulin (EF495259.1; forward, 5'-GAGGGTGA GTGAGCAGTTC-3'; reverse, 5'-CTTCATCGTCATCTGCTGTC-3'), and ubiquitin-conjugating protein (AY486137.1; forward, 5'-TGTCCATCTGCTCTCTGTTG-3'; reverse, 5'-CAC CCCAAGCACAATAAGAC-3'). Relative quantification of gene expression was calculated with the Delta-Delta $\mathrm{Ct}$ method.

\section{Statistical analysis}

Values are reported as means \pm standard error. Data were analyzed using analysis of variance (SAS 8.2, North Carolina State University, USA) and mean separation was analyzed using the least significant difference. The $\mathrm{P}$ value $<0.05$ was considered to be significant.

\section{RESULTS}

\section{Effect of ABA on visual symptoms of pepper leaf damage during chilling stress}

ABA was effective in reducing visual symptoms of damage to pepper seedlings subjected to chilling stress (Table 1). After 2 days of exposure, ABA-treated seedlings were slightly damaged ( $<5 \%$ of the leaf area was necrotic), whereas untreated plants exhibited typical chilling injury symptoms at moderate to severe levels ( $>25 \%$ of the leaf area was necrotic). Some leaves treated with distilled water displayed significant withering. However, some of the leaf tips from the ABA treatment group were only curled, and some even remained fully expanded.

\footnotetext{
Table 1. Effect of abscisic acid (ABA) applications on the degree of visual damage of pepper seedlings subjected to chilling stress.

\begin{tabular}{lc}
\hline Treatments & Visual damage index \\
\hline ABA+chilling & $1.73 \pm 0.20^{\mathrm{b}}$ \\
Chilling & $3.50 \pm 0.26^{\mathrm{a}}$ \\
\hline
\end{tabular}

Values are reported as means $\pm \mathrm{SE}(\mathrm{N}=8)$. Means followed by different superscript letters are significantly different at $\mathrm{P}<0.05$ according to the least significant difference (LSD) test.
}

\section{Effect of $\mathrm{ABA}$ on MDA and $\mathrm{H}_{2} \mathrm{O}_{2}$ levels in pepper leaves under chilling stress}

Significant increases in the MDA (Figure 1A) and $\mathrm{H}_{2} \mathrm{O}_{2}$ (Figure 1B) levels were observed owing to chilling stress (except at $120 \mathrm{~h}$ ), which reached 188 and $122 \%$, respectively, of the control group levels at $6 \mathrm{~h}(\mathrm{P}<0.05)$. ABA pretreatment also increased the MDA (except at $3 \mathrm{~h}$ ) and $\mathrm{H}_{2} \mathrm{O}_{2}$ (except at $120 \mathrm{~h}$ ) levels in the non-stressed seedlings. However, compared with plants treated with chilling, the ABA-pretreated seedlings showed reduced MDA and $\mathrm{H}_{2} \mathrm{O}_{2}$ levels when exposed to chilling stress, especially at $3 \mathrm{~h}(\mathrm{P}<0.05)$. The chilling stress significantly increased MDA and $\mathrm{H}_{2} \mathrm{O}_{2}$ levels of pepper leaves, whereas exogenous ABA distinctly decreased them. 

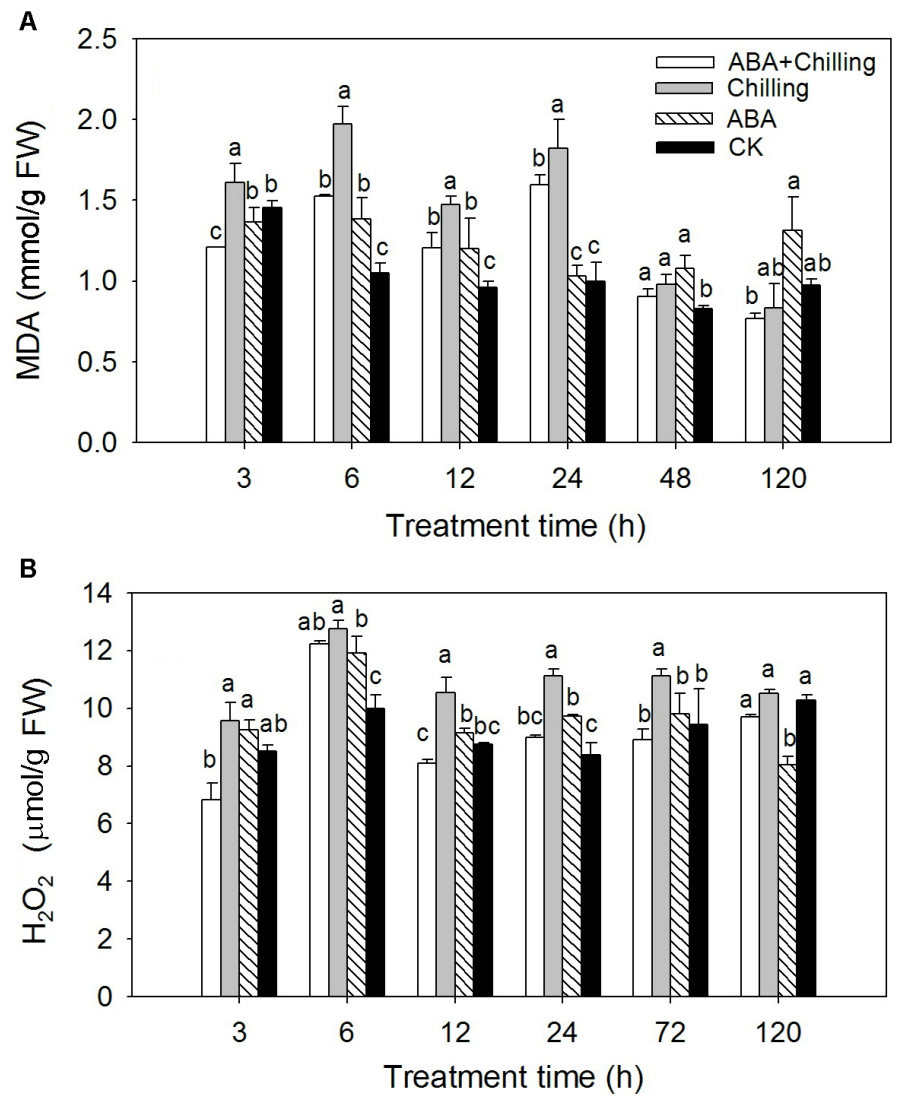

Figure 1. Time course of changes in malondialdehyde (MDA) (A) and $\mathrm{H}_{2} \mathrm{O}_{2}(\mathbf{B})$ levels in pepper leaves. Seventytwo hours after application of $0.57 \mathrm{mM}$ abscisic acid (ABA) by foliar spray, the plants were subjected to chilling stress at $10^{\circ} / 6^{\circ} \mathrm{C}$ (day/night). The plants were submitted to four treatments: $\mathrm{CK}=$ untreated; Chilling = chilling stress; $\mathrm{ABA}=$ pretreated with $0.57 \mathrm{mM} \mathrm{ABA} ; \mathrm{ABA}+$ Chilling $=$ pretreated with $0.57 \mathrm{mM}$ ABA and chilling stress. The plants were harvested 3,6,12,24, 48, 72, and $120 \mathrm{~h}$ after the start of chilling stress. The values indicate means $+\mathrm{SE}$. Means denoted with different letters are significantly different at $\mathrm{P}<0.05$ according to the least significant difference (LSD) test. FW = fresh weight.

\section{Effect of ABA on metabolites of the AsA-GSH cycle in pepper leaves under chilling stress}

The GR (Figure 2A), DHAR (Figure 2B), and MDHAR (Figure 2C) activities followed the same general trend throughout the experimental period during chilling treatments, i.e., they increased up to 12 or $24 \mathrm{~h}$ and then decreased, implying that the AsA-GSH cycle plays a positive role in mitigating chilling stress within a certain range. Compared to the $\mathrm{CK}$ group, the group treated with chilling stress and ABA pretreatment displayed elevated GR, DHAR, and MDAHR activities. The activities of these enzymes in the chilling-stressed plants were 28,70 , and $37 \%$ higher, respectively, than that of CK at $12 \mathrm{~h}$. The GR and MDAHR activities of plants treated with chilling stress were higher than those in the ABA + chilling treatment group, indicating that the effects of both exogenous ABA and chilling stress on the 
GR and MDAHR enzymes were simply not correlated. DHAR activity of the ABA + chilling treatment group was lower $(\mathrm{P}<0.05)$ at $12 \mathrm{~h}$ than that of the chilling-stressed group, but with an increase in time about $24 \mathrm{~h}$ it became higher.
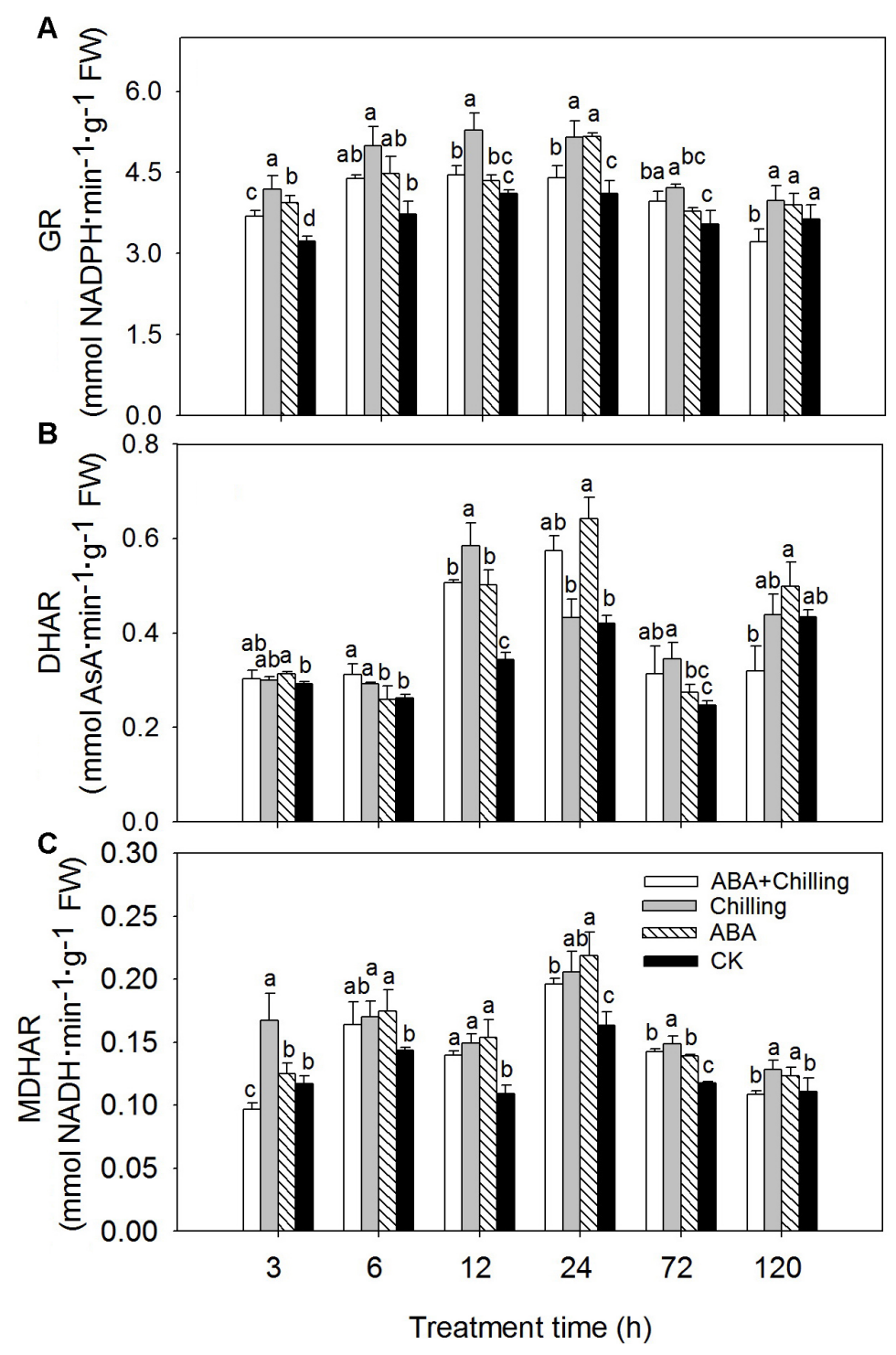

Figure 2. Time course of total glutathione reductase (GR) (A), dehydroascorbate reductase (DHAR) (B) and monoDHAR (MDHAR) (C) activities in the leaves of pepper plants. Seventy-two hours after application of $0.57 \mathrm{mM}$ abscisic acid (ABA) by foliar spray, the plants were subjected to chilling stress at $10^{\circ} / 6^{\circ} \mathrm{C}$ (day/night). The plants were submitted to four treatments: $\mathrm{CK}=$ untreated; Chilling = chilling stress; $\mathrm{ABA}=$ pretreated with $0.57 \mathrm{mM} \mathrm{ABA} ; \mathrm{ABA}$ + Chilling = pretreated with $0.57 \mathrm{mM} \mathrm{ABA}$ and chilling stress. The plants were harvested 3, 6, 12, 24, 72, and $120 \mathrm{~h}$ after the start of chilling stress. The values indicate means + SE. Means denoted with different letters are significantly different at $\mathrm{P}<0.05$ according to the least significant difference (LSD) test. $\mathrm{FW}=$ fresh weight. 
Compared with controls, plants under chilling stress displayed increased AsA (except at $3 \mathrm{~h}$ ) and GSH levels throughout the experimental period, whereas ABA pretreatment lowered AsA (except at $6 \mathrm{~h}$ ) and GSH levels. Treatment in the ABA + chilling group increased AsA and GSH to levels lower than those of chilling treatment alone. These results indicate that the enhancement of AsA and GSH levels is correlated with both exogenous ABA and chilling stress. The chilling-induced increases in AsA and GSH levels were nearly $180 \%$ at $12 \mathrm{~h}$ and $170 \%$ of those of both control and ABA-pretreated plants at $6 \mathrm{~h}$. Regardless of ABA or distilled water pretreatment after chilling stress for $72 \mathrm{~h}$, the level of GSH/GSSG (Figure 3C) was significantly increased relative to that of $\mathrm{CK}$, showing that the pepper seedlings became more tolerant (this result was in line with the above-mentioned trends of MDA and $\mathrm{H}_{2} \mathrm{O}_{2}$ levels; Figure $1 \mathrm{~A}$ and $\mathrm{B}$ ).

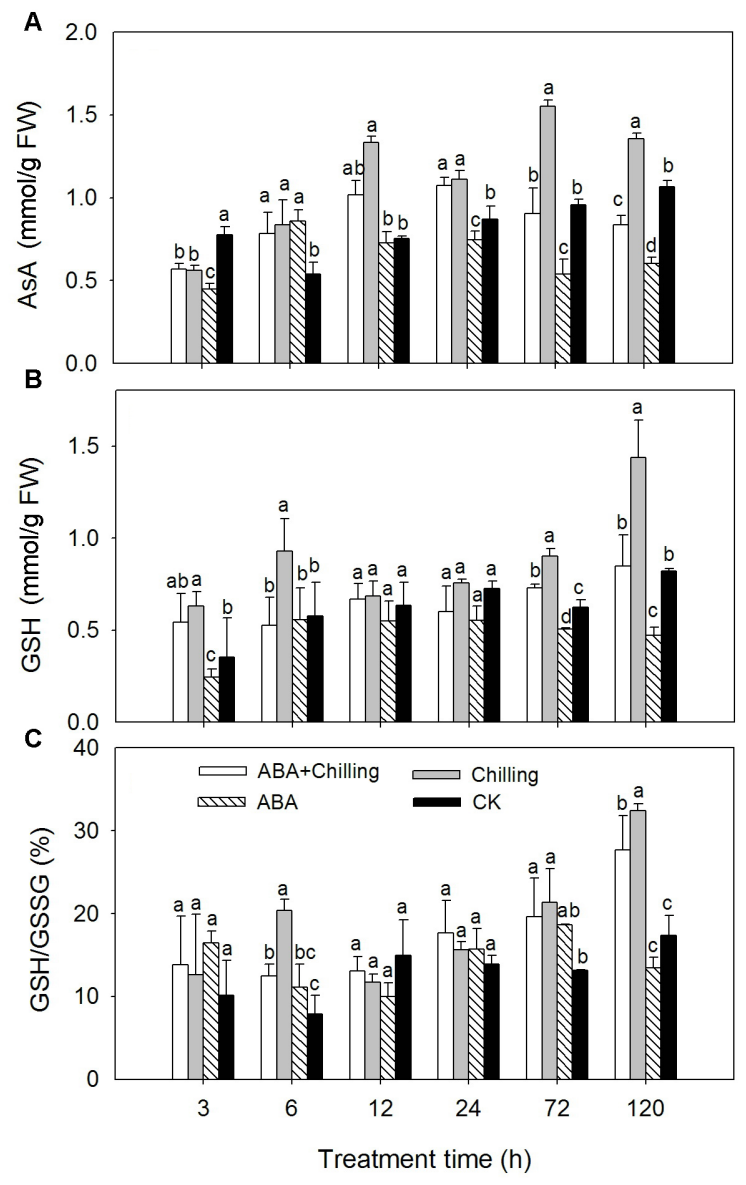

Figure 3. Time course of ascorbate (AsA) (A) and glutathione (GSH) (B) levels and the GSH/GSSG (C) ratio in the leaves of pepper plants. Seventy-two hours after application of $0.57 \mathrm{mM}$ abscisic acid (ABA) by foliar spray, the plants were subjected to chilling stress at $10 \% 6^{\circ} \mathrm{C}$ (day/night). The plants were submitted to four treatments: $\mathrm{CK}=$ untreated; Chilling $=$ chilling stress; $\mathrm{ABA}=$ pretreated with $0.57 \mathrm{mM} \mathrm{ABA} ; \mathrm{ABA}+$ Chilling $=$ pretreated with $0.57 \mathrm{mM} \mathrm{ABA}$ and chilling stress. The plants were harvested 3, 6, 12, 24, 72, and $120 \mathrm{~h}$ after the start of chilling stress. The values indicate means $+\mathrm{SE}$. Means denoted with different letters are significantly different at $\mathrm{P}<0.05$ according to the least significant difference (LSD) test. $\mathrm{FW}=$ fresh weight. 


\section{Effect of ABA on antioxidant enzyme activities in pepper leaves under chilling stress}

The time course of total SOD activity in leaves showed a transient decrease at 12 $\mathrm{h}$ and then an increase until the end of the experimental period in 3 treatments (Figure 4). Compared to that of CK, SOD activity decreased during $24 \mathrm{~h}$ of chilling treatment, whereas ABA pretreatment elevated SOD activity. Moreover, the SOD activity from chilling stress was lower than that in the ABA + chilling group. SOD activity in both the ABA-pretreated and the ABA + chilling plants was 36 and $30 \%$ higher than that of chilling-stressed plants at $3 \mathrm{~h}$. Therefore, exogenous ABA enabled cv. 'P70' seedlings to increase SOD activity during exposure to both normal and low temperatures.

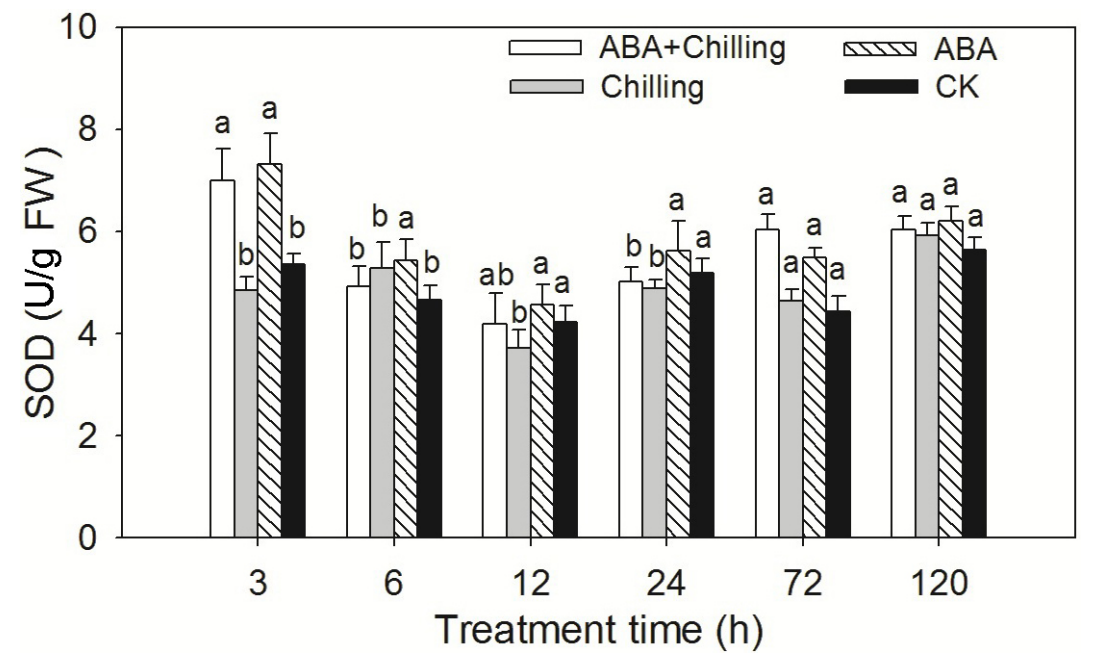

Figure 4. Time course of the total superoxide dismutase (SOD) activity in the leaves of pepper plants. Seventy-two hours after application of $0.57 \mathrm{mM}$ abscisic acid (ABA) by foliar spray, the plants were subjected to chilling stress at $10^{\circ} / 6^{\circ} \mathrm{C}$ (day/night). The plants were submitted to four treatments: $\mathrm{CK}=$ untreated; Chilling = chilling stress; $\mathrm{ABA}$ $=$ pretreated with $0.57 \mathrm{mM} \mathrm{ABA} ; \mathrm{ABA}+$ Chilling = pretreated with $0.57 \mathrm{mM}$ ABA and chilling stress. The plants were harvested 3, 6, 12, 24, 72, and $120 \mathrm{~h}$ after the start of chilling stress. The values indicate means + SE. Means denoted with different letters are significantly different at $\mathrm{P}<0.05$ according to the least significant difference (LSD) test. $\mathrm{FW}=$ fresh weight.

Time courses of the total POD, CAT, and APX activities in the leaves of the pepper plants are shown in Figure 5. POD activity in chilling-stressed plants reached a maximum at 6 $\mathrm{h}$ and then abruptly decreased until the end of the experimental period. Chilling stress elevated APX activity throughout the experimental period and CAT activity after $48 \mathrm{~h}$ relative to that of CK. Exogenous ABA significantly $(\mathrm{P}<0.05)$ increased CAT and APX activities. The combination of ABA pretreatment and chilling stress resulted in the highest POD enzyme activity but lower CAT (except at $3 \mathrm{~h}$ ) and APX activities than those in chilling-stressed plants during the entire study. Moreover, the POD activity of ABA + chilling plants was approximately $55 \%$ (at $12 \mathrm{~h}$ ) and $28 \%$ (at $48 \mathrm{~h}$ ) higher $(\mathrm{P}<0.05)$ than that in plants treated with chilling. Thus, we infer that ABA induced CAT and APX activities at normal temperatures but not at low temperatures. 


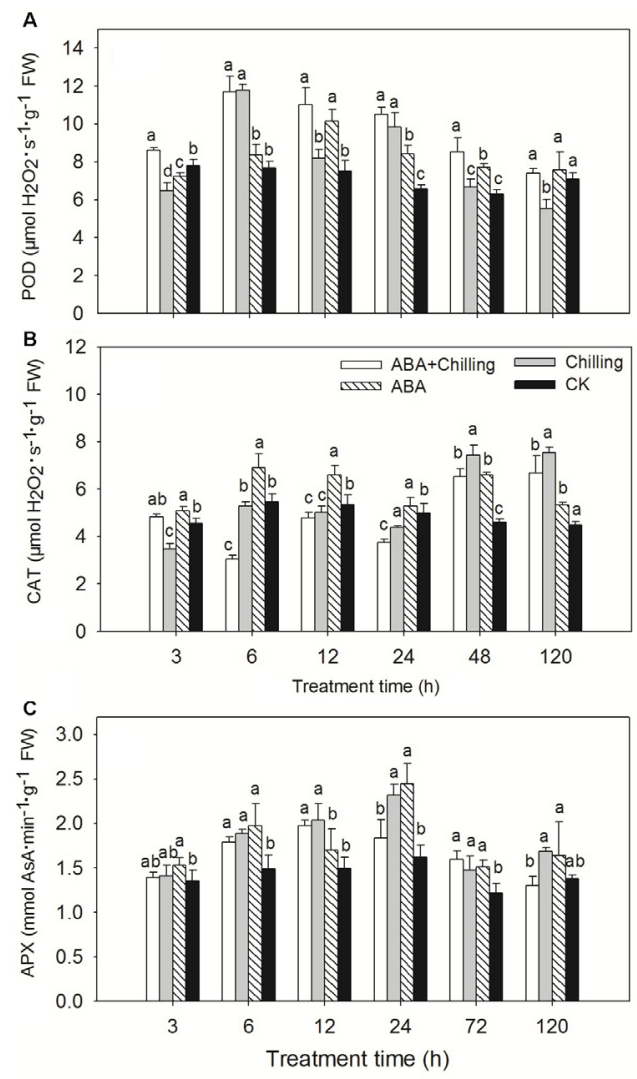

Figure 5. Time courses of the total guaiacol peroxidase (POD) (A), catalase (CAT) (B) and ascorbate peroxidase (APX) (C) activities in the leaves of pepper plants. Seventy-two hours after application of $0.57 \mathrm{mM}$ abscisic acid (ABA) by foliar spray, the plants were subjected to chilling stress at $10^{\circ} / 6^{\circ} \mathrm{C}$ (day/night). The plants were submitted to four treatments: $\mathrm{CK}=$ untreated; Chilling = chilling stress; $\mathrm{ABA}=$ pretreated with $0.57 \mathrm{mM} \mathrm{ABA}$; $\mathrm{ABA}+$ Chilling = pretreated with $0.57 \mathrm{mM} \mathrm{ABA}$ and chilling stress. The plants were harvested 3, 6, 12, 24, 48, 72, and $120 \mathrm{~h}$ after the start of chilling stress. The values indicate means + SE. Means denoted with different letters are significantly different at $\mathrm{P}<0.05$ according to the least significant difference (LSD) test. $\mathrm{FW}=$ fresh weight.

\section{Effect of ABA on antioxidant gene expression in pepper leaves under chilling stress}

To analyze the molecular mechanisms underlying ABA-induced chilling stress tolerance, we performed qRT-PCR analysis of stress-responsive genes (Figure 6). In this study, chilling stress for $0 \mathrm{~h}$ was used as a control. Compared to the control, chilling stress for $3 \mathrm{~h}$ triggered the expression of Mn-SOD, POD, DHAR1, and DHAR2 genes significantly and, conversely, inhibited the expression of these genes when chilling stress was induced for 12 h. The ABA + chilling plants showed greater expression of $M n-S O D, P O D$ genes than that in chilling-stressed plants throughout the experimental period (Figure 6A and $\mathrm{B}$ ). Compared to plants treated with chilling, plants treated with $\mathrm{ABA}+$ chilling (Figure $6 \mathrm{C}$ and $\mathrm{D}$ ) displayed significantly higher transcript levels of DHAR1 and DHAR2 at $0-1 \mathrm{~h}$ that lowered abruptly at 3-6 $\mathrm{h}$ before becoming distinctly higher again after $24 \mathrm{~h}$. Notably, exogenous ABA upregu- 
lated DHAR1 and DHAR2 expression in pepper seedlings under chilling stress for $24 \mathrm{~h}$. The highest expression level of $M n-S O D, P O D, D H A R 1$, and DHAR2 were 5.01, 3.41, 3.07, and 2.27 times higher, respectively, than levels in the chilling-stressed plants.
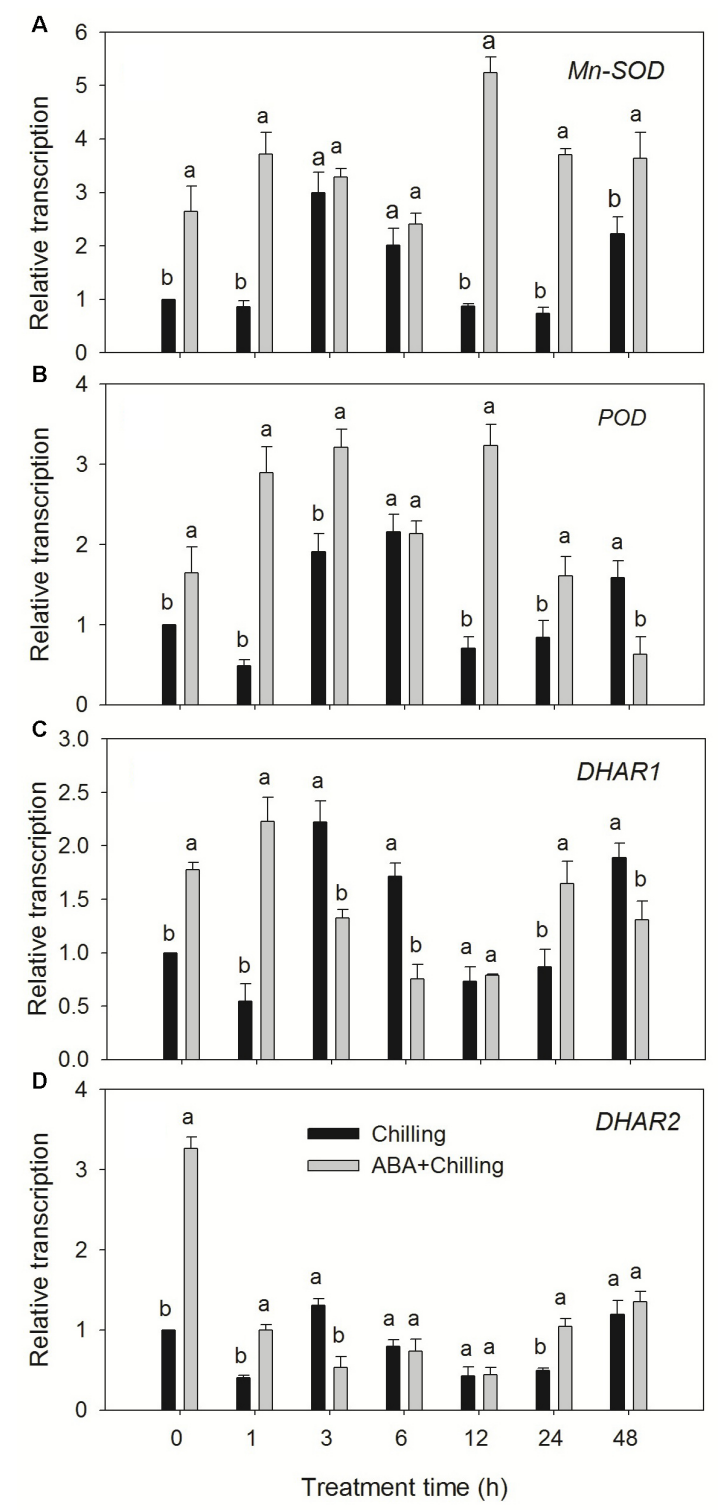

Figure 6. Time courses of Mn-SOD (A), POD (B), DHAR1 (C), and DHAR2 (D) gene expression in the leaves of pepper plants. Seventy-two hours after application of $0.57 \mathrm{mM}$ abscisic acid (ABA) by foliar spray, the plants were subjected to chilling stress at $10^{\circ} / 6^{\circ} \mathrm{C}$ (day/night). The plants were submitted two treatments: Chilling $=$ chilling stress; $\mathrm{ABA}+$ Chilling $=$ pretreated with $0.57 \mathrm{mM} \mathrm{ABA}$ and chilling stress. The plants were harvested $0,1,3,6,12$, 24 , and $48 \mathrm{~h}$ after the start of chilling stress. The values indicate means $+\mathrm{SE}$. Means denoted with different letters are significantly different at $\mathrm{P}<0.05$ according to the least significant difference (LSD) test. 


\section{DISCUSSION}

\section{Effect of $A B A$ on visual symptoms of pepper leaf damage under chilling stress}

The data presented in this study indicate that plants pretreated with ABA exhibited slightly less damage and had smaller necrotic areas on leaf edges (Table 1), but those that were not pretreated with ABA had moderate damage that caused significant withering. These results demonstrate a protective effect of $A B A$ in response to chilling injury in pepper seedlings, suggesting that $A B A$ pretreatment effectively protects pepper leaves against dehydration during chilling stress.

\section{Effect of ABA on MDA and $\mathrm{H}_{2} \mathrm{O}_{2}$ levels in pepper leaves under chilling stress}

Cold stress induces dehydration, which eventually leads to wilting and results in membrane disintegration. MDA is an indicator of the extent of cell membrane injury. Therefore, MDA level is related to the severity of the visual damage index. Chilling stress increases MDA and $\mathrm{H}_{2} \mathrm{O}_{2}$ levels ( $\mathrm{Li}$ et al., 2011), and treatment with ABA decreases them (Nayyar et al., 2005). In our study, chilling stress significantly increased MDA and $\mathrm{H}_{2} \mathrm{O}_{2}$ levels in pepper seedlings (Figure 1), indicating that antioxidant enzymes are an insufficient defense system. ABA pretreatment in chilling-stressed seedlings significantly lowered levels of these compounds compared with levels under chilling stress alone, indicating that ABA has a protective effect via lowered levels of MDA and $\mathrm{H}_{2} \mathrm{O}_{2}$ during abiotic stress conditions.

\section{Effect of ABA on antioxidant enzyme activities in pepper leaves under chilling stress}

Abiotic stresses increase ROS levels in plants, and the resistance or susceptibility of the plant has been related to the proportion and functional efficiency of a network of low molecular weight antioxidants and ROS-scavenging enzymes. In this context, in addition to CAT, SOD, and other POD, the AsA-GSH cycle is a first line of defense against the deleterious effects of ROS. Recent studies have shown that ABA protects plants from several types of abiotic stresses by enhancing antioxidant capacity (Ding et al., 2010; Wang et al., 2011). In this study, we investigated the possible regulatory role of exogenous ABA on AsA and GSH levels and the metabolites of the AsA-GSH cycle, including APX, DHAR, MDHAR, and GR. The working hypothesis was that via antioxidative properties, ABA can alleviate oxidative stress in plants under chilling stress.

In plants, MDHAR and DHAR are responsible for regenerating AsA and play an important role in antioxidant defense. GR is a major antioxidant enzyme that belongs to the AsAGSH cycle, and this enzyme is responsible for the reduction of GSSG to GSH using NADPH. In our study, chilling stress raised the activities of GR, DHAR, and MDHAR in the pepper seedlings, indicating that AsA and GSH are highly regenerated to scavenge ROS (Figure 2). Our results are supported by evidence from other researchers (Zhang et al., 2009). Conversely, compared with seedlings under chilling stress alone, seedlings pretreated with $\mathrm{ABA}$ that were exposed to chilling stress showed lower activities of the above-mentioned enzymes. The result may be relevant to the extent that oxidative stress in plants from the $\mathrm{ABA}+$ chilling group was insufficient to enhance the AsA recycling pathway (the effect of $A B A$ on visual symptoms of damage and MDA and $\mathrm{H}_{2} \mathrm{O}_{2}$ levels under chilling stress supported this hypothesis; Table 1 and Figure 1), which means the GR, DHAR, MDHAR activities were lower than that in chilling 
stress group, but there was except that seedlings pretreated with ABA under chilling stress showed higher DHAR activity than that of plants in the chilling-stressed group at $24 \mathrm{~h}$. The result was consistent with the findings described below, that AsA level in plants treated with $\mathrm{ABA}+$ chilling increased almost to the same level as that observed in plants treated with chilling at $24 \mathrm{~h}$. This result means that exogenous ABA increases the AsA level in pepper seedlings under chilling stress, mainly owing to the activity of the DHAR enzyme.

Studies have demonstrated the important roles of AsA and GSH in the tolerance of plants to environmental stresses. For instance, low temperature increases AsA and GSH levels in cucumber leaves ( $\mathrm{Li}$ et al., 2011), and increased AsA content in Arabidopsis, through the enhanced recycling pathway, reduces the deleterious effects of environmental oxidative stress (Wang et al., 2010). In the present study, the AsA and GSH levels in the pepper seedlings increased under chilling stress (Figure 3). This result might be due to enhanced MDHAR, DHAR, and GR activities at this level of chilling stress. The higher levels of AsA and GSH coincided with a trend toward decreasing $\mathrm{H}_{2} \mathrm{O}_{2}$ levels, suggesting that the enhancement of AsA and GSH levels is involved in ROS-scavenging in pepper leaves during chilling stress. Conversely, ABA-pretreated seedlings under chilling stress displayed decreased AsA and GSH levels compared with those of seedlings exposed to chilling only. These results coincided with changes in AsA recycling-related enzymes (APX, GR, DHAR, and MDHAR), indicating that the AsA recycling pathway is not enhanced by exogenous ABA in pepper seedlings under chilling stress. Our results differ slightly from those reporting that other exogenous applications induced AsA, GSH, and the AsA-related enzymes during abiotic stress (Liu et al., 2010; Shan and Liang, 2010). The dissimilar results were likely influenced by plant species, the duration and severity of stress, and differences in exogenous applications. However, exogenous ABA has a protective effect in mitigating visual symptoms of damage and MDA and $\mathrm{H}_{2} \mathrm{O}_{2}$ levels in pepper seedlings under chilling stress (Table 1 and Figure 1). Therefore, we speculated other antioxidant enzymes, mainly scavenge excess ROS in chillingstressed pepper plants pretreated with ABA.

The enzyme SOD dismutates $\mathrm{O}^{2-}$ into $\mathrm{H}_{2} \mathrm{O}_{2}$ with high efficiency in various cell organelles. Chilling stress significantly decreased SOD activity in cucumbers (Zhang et al., 2009). ABA pretreatment induced SOD enzyme activity under drought stress (Wang et al., 2011). In our study, chilling stress decreased SOD activity before $24 \mathrm{~h}$ (Figure 4) compared to that in controls, subsequently leading to excessive accumulation of $\mathrm{H}_{2} \mathrm{O}_{2}$ and MDA (Figure 1). Compared to the activity in the chilling treatment group, SOD activity increased in the leaves of $\mathrm{ABA}+$ chilling plants, suggesting that the plants sprayed with $\mathrm{ABA}$ had better $\mathrm{O}^{2-}$-scavenging capability under chilling stress. Chilling tolerance was directly related to the increase in SOD activity (de Azevedo Neto et al., 2005).

SOD mitigates the detoxification of $\mathrm{O}^{2-}$ by forming $\mathrm{H}_{2} \mathrm{O}_{2}$, which is also toxic. In plants, a number of enzymes are related to $\mathrm{H}_{2} \mathrm{O}_{2}$ metabolism - mainly CAT, APX and POD. Chilling stress enhanced the activities of APX, GR, and POD enzymes, whereas it decreases CAT activity in cucumber leaves (Lee and Lee, 2000). ABA pretreatment activated SOD and POD under abiotic stress in another study (Wang et al., 2011). In our study, chilling stress increased POD (Figure 5A) and APX activity (Figure 5C) but decreased CAT activity before $24 \mathrm{~h}$ (Figure 5B), suggesting that the protective mechanism against ROS is, at least, dependent on POD and APX enzymes in the leaves of pepper cv. 'P70' and is coordinated with SOD and CAT enzymes. Nevertheless, the level of $\mathrm{H}_{2} \mathrm{O}_{2}$ was highest in the chilling treatment plants (Figure 1B), indicating that the generation of endogenous $\mathrm{H}_{2} \mathrm{O}_{2}$ exceeds the capacity of the cellular antioxidant defense system. This decrease 
in CAT activity might be due to its inactivation by accumulated $\mathrm{H}_{2} \mathrm{O}_{2}$ induced by chilling stress. Considering that chilling stress significantly induced the AsA-GSH cycle in pepper seedlings, we hypothesize that the cycle is responsible for coping with high concentrations of $\mathrm{H}_{2} \mathrm{O}_{2}$ when CAT becomes inactivated. This hypothesis is supported by other reports (Lee and Lee, 2000). Relative to chilling stress alone, ABA-pretreated seedlings displayed increased POD activity and decreased CAT and APX enzyme activities under chilling stress. These results, together with the increased SOD activity in chilled plants pretreated with ABA, suggest that pretreatment with exogenous $\mathrm{ABA}$ increases the capability of pepper leaves to scavenge excessive $\mathrm{O}^{2-}$ and $\mathrm{H}_{2} \mathrm{O}_{2}$, under chilling stress, mainly via the SOD and POD enzymes.

$\mathrm{ABA}$ is known to play an important role in improving cold stress tolerance and triggering leaf senescence. The ABA signaling pathway participates in the regulatory network of cold and leaf senescence pathways involving other signaling molecules such as sugars and ROS. A recent report has suggested that ABA induces the accumulation of MDA and $\mathrm{H}_{2} \mathrm{O}_{2}$ in senescing rice leaf, which in turn accelerates leaf senescence (Hung and Kao, 2004). ABA also enhances the activities of antioxidative enzymes such as SOD, APX, and GR, thus protecting the cellular functions required for the progression and completion of senescence (Hung and Kao, 2003). In our study, ABA pretreatment under room temperature conditions significantly increased MDA and $\mathrm{H}_{2} \mathrm{O}_{2}$ levels (Figure 1) and the activities of GR, DHAR, MDHAR, SOD, POD, CAT, and APX (Figures 2, 4, and 5), whereas decreased AsA and GSH levels (Figure 3) in pepper seedlings led to a response similar to that of ABA-induced senescence mentioned above (Hung and Kao 2003, 2004).

\section{Effect of ABA on antioxidant gene expressions in pepper leaves under chilling stress}

$M n-S O D$ expression reportedly responds strongly to chilling and oxidative stress (Lee and Lee, 2000; Li et al., 2009), and ABA induces its expression (Bueno et al., 1998). In the present study, pretreating plants with $\mathrm{ABA}$ enhanced chilling tolerance by inducing gene expression, such as that of $M n-S O D$ and $P O D$, involved in oxidative stress defense mechanisms. Notably, ABA pretreatment significantly enhanced the transcript level of DHAR1 and DHAR2 genes under chilling stress for $24 \mathrm{~h}$, which is well in line with the enzyme activity of DHAR (Figure 2B). Overall, ABA-mediated SOD, POD, and DHAR activity changes seemed to be regulated at the transcriptional level. ABA-induced expression of antioxidant genes may contribute to the enhancement of cold tolerance by managing cold stress-induced ROS production (Xue-Xuan et al., 2010).

In conclusion, our study provided insight into the role of ABA in regulating physiological and biochemical responses to chilling stress. Exogenous ABA application is an effective way to improve cold tolerance. This finding may be partially attributed to the obvious enhancement of SOD and POD activities and related gene expression, which are closely related to the AsA-GSH cycle in pepper seedlings under chilling stress. Complete elucidation of the roles of ABA and the detailed protective mechanisms that plants use will be helpful in developing plants that are more stress tolerant. Further studies related to our findings may help determine the mechanism of ABA-induced cold tolerance correlated to leaf senescence.

\section{ACKNOWLEDGMENTS}

Research supported by the National Natural Science Foundation of China (\#30571262,\#31000906), the National High Technology Research and Development Program 
(\#2009AA10Z104-6), the Natural Science Foundation of Shaanxi Province (\#2011JQ3010), the Doctorate Program of the University of Ministry of Education (\#20090204120005), the Young Academic Backbone Support Program of Northwest A\&F University (\#Z111020711), and the Chinese Universities Scientific Fund (\#QN2009010). Language help was provided by Elsevier Webshop language services.

\section{REFERENCES}

Aebi H (1984). Catalase in vitro. Methods Enzymol. 105: 121-126.

Arrigoni O, Dipierro S and Borraccino G (1981). Ascorbate free radical reductase; a key enzyme of the ascorbic acid system. FEBS Lett. 125: 242-244.

Bellaire BA, Carmody J, Braud J, Gossett DR, et al. (2000). Involvement of abscisic acid-dependent and -independent pathways in the upregulation of antioxidant enzyme activity during $\mathrm{NaCl}$ stress in cotton callus tissue. Free Radic. Res. 33: 531-545.

Bueno P, Piqueras A, Kurepa J, Savouré A, et al. (1998). Expression of antioxidant enzymes in response to abscisic acid and high osmoticum in tobacco BY-2 cell cultures. Plant Sci. 138: 27-34.

de Azevedo Neto AD, Prisco JT, Eneas-Filho J, Medeiros JV, et al. (2005). Hydrogen peroxide pre-treatment induces saltstress acclimation in maize plants. J. Plant Physiol. 162: 1114-1122.

Dhindsa RS, Plumb-Dhindsa P and Thorpe TA (1981). Leaf senescence: correlated with increased levels of membrane permeability and lipid peroxidation, and decreased levels of superoxide dismutase and catalase. J. Exp. Bot. 32: 93-101.

Ding W, Song L, Wang X and Bi Y (2010). Effect of abscisic acid on heat stress tolerance in the calli from two ecotypes of Phragmites communis. Biol. Plantarum 54: 607-613.

Ghassemian M, Lutes J, Chang HS, Lange I, et al. (2008). Abscisic acid-induced modulation of metabolic and redox control pathways in Arabidopsis thaliana. Phytochemistry 69: 2899-2911.

Giannopolitis CN and Ries SK (1977). Superoxide dismutases: I. Occurrence in higher plants. Plant Physiol. 59: 309-314.

Griffith OW (1980). Determination of glutathione and glutathione disulfide using glutathione reductase and 2-vinylpyridine. Anal. Biochem. 106: 207-212.

Hammerschmidt R, Nuckles EM and Kuc J (1982). Association of enhanced peroxidase activity with induced systemic resistance of cucumber to Colletotrichum lagenarium. Physiol. Plant Pathol. 20: 73-82.

Hodges DM, Lester GE, Munro KD and Toivonen PM (2004). Oxidative stress: importance for postharvest quality. HortScience 39: 924-929.

Hung KT and Kao CH (2003). Nitric oxide counteracts the senescence of rice leaves induced by abscisic acid. J. Plant Physiol. 160: 871-879.

Hung KT and Kao CH (2004). Hydrogen peroxide is necessary for abscisic acid-induced senescence of rice leaves. J. Plant Physiol. 161: 1347-1357.

Jiang M and Zhang J (2002). Role of abscissic acid in water stress-induced antioxidant defense in leaves of maize seedlings. Free Radic. Res. 36: 1001-1015.

Korkmaz A, Korkmaz Y and Demirkiran AR (2010). Enhancing chilling stress tolerance of pepper seedlings by exogenous application of 5-aminolevulinic acid. Environ. Exp. Bot. 67: 495-501.

Le Martret B, Poage M, Shiel K, Nugent GD, et al. (2011). Tobacco chloroplast transformants expressing genes encoding dehydroascorbate reductase, glutathione reductase, and glutathione-S-transferase, exhibit altered anti-oxidant metabolism and improved abiotic stress tolerance. Plant Biotechnol. J. 9: 661-673.

Lee DH and Lee CB (2000). Chilling stress-induced changes of antioxidant enzymes in the leaves of cucumber: in gel enzyme activity assays. Plant Sci. 159: 75-85.

Li Q, Yu B, Gao Y, Dai AH, et al. (2011). Cinnamic acid pretreatment mitigates chilling stress of cucumber leaves through altering antioxidant enzyme activity. J. Plant Physiol. 168: 927-934.

Li W, Qi L, Lin X, Chen H, et al. (2009). The expression of manganese superoxide dismutase gene from Nelumbo nucifera responds strongly to chilling and oxidative stresses. J. Integr. Plant Biol. 51: 279-286.

Li Y, Liu Y and Zhang JG (2010). Advances in the research on the AsA-GSH cycle in horticultural crops. Front. Agric. China 4: 84-90.

Liu ZJ, Guo YK and Bai JG (2010). Exogenous hydrogen peroxide changes antioxidant enzyme activity and protects ultrastructure in leaves of two cucumber ecotypes under osmotic stress. J. Plant Growth Regul. 29: 171-183.

Logan BA, Grace SC, Adams WW and Demmig-Adams B (1998). Seasonal differences in xanthophyll cycle characteristics and antioxidants in Mahonia repens growing in different light environments. Oecologia 116: 9-17.

Genetics and Molecular Research 11 (4): 4063-4080 (2012)

CFUNPEC-RP www.funpecrp.com.br 
Ma XW, Ma FW, Mi YF, Ma YH, et al. (2008). Morphological and physiological responses of two contrasting malus species to exogenous abscisic acid application. Plant Growth Regul. 56: 77-87.

Mukherjee SP and Choudhuri MA (1983). Implications of water stress-induced changes in the levels of endogenous ascorbic acid and hydrogen peroxide in vigna seedlings. Physiol. Plant. 58: 166-170.

Nakano Y and Asada K (1981). Hydrogen peroxide is scavenged by ascorbate-specific peroxidase in spinach chloroplasts. Plant Cell Physiol. 22: 867-880.

Nayyar H, Bains TS and Kumar S (2005). Chilling stressed chickpea seedlings: effect of cold acclimation, calcium and abscisic acid on cryoprotective solutes and oxidative damage. Environ. Exp. Bot. 54: 275-285.

Schaedle M (1977). Chloroplast glutathione reductase. Plant Physiol. 59: 1011-1012.

Selote DS and Khanna-Chopra R (2006). Drought acclimation confers oxidative stress tolerance by inducing co-ordinated antioxidant defense at cellular and subcellular level in leaves of wheat seedlings. Physiol. Plant. 127: 494-506.

Shan C and Liang Z (2010). Jasmonic acid regulates ascorbate and glutathione metabolism in Agropyron cristatum leaves under water stress. Plant Sci. 178: 130-139.

Stevens R, Page D, Gouble B, Garchery C, et al. (2008). Tomato fruit ascorbic acid content is linked with monodehydroascorbate reductase activity and tolerance to chilling stress. Plant Cell Environ. 31: 1086-1096.

Verslues PE and Zhu JK (2005). Before and beyond ABA: upstream sensing and internal signals that determine ABA accumulation and response under abiotic stress. Biochem. Soc. Trans. 33: 375-379.

Wan H, Yuan W, Ruan M, Ye Q, et al. (2011). Identification of reference genes for reverse transcription quantitative realtime PCR normalization in pepper (Capsicum annuum L.). Biochem. Biophys. Res. Commun. 416: 24-30.

Wang YL, Ma FW, Li MJ, Liang D, et al. (2011). Physiological responses of kiwifruit plants to exogenous ABA under drought conditions. Plant Growth Regul. 64: 63-74.

Wang Z, Xiao Y, Chen W, Tang K, et al. (2010). Increased vitamin C content accompanied by an enhanced recycling pathway confers oxidative stress tolerance in Arabidopsis. J. Integr. Plant Biol. 52: 400-409.

Xue-Xuan X, Hong-Bo S, Yuan-Yuan M, Gang X, et al. (2010). Biotechnological implications from abscisic acid (ABA) roles in cold stress and leaf senescence as an important signal for improving plant sustainable survival under abioticstressed conditions. Crit. Rev. Biotechnol. 30: 222-230.

Zhang W, Jiang B, Li W, Song H, et al. (2009). Polyamines enhance chilling tolerance of cucumber (Cucumis sativus L.) through modulating antioxidative system. Sci. Hortic. 122: 200-208.

Zhang Y, Tang HR, Luo Y and Hou YX (2009). Responses of antioxidant enzymes and compounds in strawberry (Fragaria $\mathrm{x}$ ananassa 'Toyonaka') to cold stress. New Zeal J. Crop Hort. 37: 383-390.

Zhou BY, Guo ZF and Liu ZL (2005). Effects of abscisic acid on antioxidant systems of Stylosanthes guianensis (Aublet) Sw. under chilling stress. Crop Sci. 45: 599-605. 